\title{
Formation of Heavy Neutron-Deficient Nuclides in 3He-Induced Reactions
}

\section{Aaltonen, J.}

2015-07

Aaltonen , J , Gromova , E A, Jakovlev , V A , Helariutta , K, Maltsev , N A, Penttilä , H , Rubchenya, V A , Trzaska, W H \& Salminen-Paatero , S 2015, ' Formation of Heavy Neutron-Deficient Nuclides in 3He-Induced Reactions ', Russian Academy of Sciences.

Bulletin. Physics, vol. 79 , no. 7 , pp. 848-851 . https://doi.org/10.3103/S1062873815070047

http://hdl.handle.net/10138/159531

https://doi.org/10.3103/S1062873815070047

Downloaded from Helda, University of Helsinki institutional repository.

This is an electronic reprint of the original article.

This reprint may differ from the original in pagination and typographic detail.

Please cite the original version. 


\section{Formation of Heavy Neutron-Deficient Nuclides in $3 \mathrm{He}$-Induced Reactions}

ARTICLE in BULLETIN OF THE RUSSIAN ACADEMY OF SCIENCES PHYSICS · JULY 2015

DOI: $10.3103 / \mathrm{S} 1062873815070047$

READS

24

9 AUTHORS, INCLUDING:

K. Helariutta

University of Helsinki

189 PUBLICATIONS $\quad 1,650$ CITATIONS

SEE PROFILE

Wladyslaw Henryk Trzaska

University of Jyväskylä

448 PUBLICATIONS $\quad \mathbf{5 , 4 1 7}$ CITATIONS

SEE PROFILE
V.A. Rubchenya

University of Jyväskylä

88 PUBLICATIONS 471 CITATIONS

SEE PROFILE

Susanna Salminen-Paatero

University of Helsinki

18 PUBLICATIONS 48 CITATIONS

SEE PROFILE 


\title{
Formation of Heavy Neutron-Deficient Nuclides in ${ }^{3} \mathrm{He}$-Induced Reactions
}

\author{
J. Aaltonen ${ }^{a}$, E. A. Gromova ${ }^{b}$, V. A. Jakovlev ${ }^{b}$, K. Helariutta ${ }^{a}$, N. A. Maltsev ${ }^{c}$, H. Penttilä ${ }^{d}$, \\ V. A. Rubchenya ${ }^{b, c, d}$, W. H. Trzaska ${ }^{d}$, and S. Salminen-Paatero ${ }^{a}$ \\ ${ }^{a}$ Department of Chemistry, University of Helsinki, O0014 Helsinki, Finland \\ ${ }^{b}$ Khlopin Radium Institute, St. Petersburg, 194021 Russia \\ ${ }^{c}$ Faculty of Physics, St. Petersburg State University, 199034 Russia \\ ${ }^{d}$ Department of Physics, University of Jyväskylä, 40014 Jyväskylä, Finland \\ e-mail:jakovlev@khlopin.ru
}

\begin{abstract}
Reactions of ${ }^{3} \mathrm{He}$ with actinide nuclei are a promising tool for the production of heavy neutrondeficient nuclei, which are of great interest as tracers in environmental studies. In this work, highly enriched ${ }^{235} \mathrm{U}$ targets $1 \mathrm{mg} \mathrm{cm}^{-2}$ thick were irradiated using ${ }^{3} \mathrm{He}$ ions with energies of $20.4-42.0 \mathrm{MeV}$ at the Accelerator Laboratory of University of Jyväskylä, Finland. The irradiated targets were analyzed with gamma and alpha spectrometers and then dissolved in order to chemically separate $\mathrm{Pu}$ and $\mathrm{Np}$ from the fission products and the target material. The chemical yields of ${ }^{234} \mathrm{~Np}$ and ${ }^{236} \mathrm{Pu}$ were determined by measuring their activities prior to and after chemical separation. Previously unknown excitation functions of the nuclides ${ }^{234,236,237} \mathrm{Pu}$ and ${ }^{234}, 235,236 m \mathrm{~Np}$ were thus found. The obtained experimental data were analyzed using the direct reaction theory for a model with nuclear friction included in the fission channel and due consideration of the preequilibrium processes.
\end{abstract}

DOI: $10.3103 / \mathrm{S} 1062873815070047$

\section{INTRODUCTION}

At present, there is little information on the interaction between ${ }^{3} \mathrm{He}$ and actinide nuclei. There have been few near-barrier measurements of the probability of fission in direct reactions of ${ }^{3} \mathrm{He}$ with actinide nuclei [1].

The special structure of the nuclide ${ }^{3} \mathrm{He}$ can produce interesting features in the excitation functions of various reaction channels. From a practical point of view, reactions induced by ${ }^{3} \mathrm{He}$ can play an important part in the production of heavy neutron-deficient nuclides that are used in environmental studies.

Ways of obtaining various short-lived $\mathrm{Np}$ and $\mathrm{Pu}$ isotopes were studied systematically in [2-4]. These works focused on the isotopes ${ }^{235} \mathrm{~Np}\left(T_{1 / 2}=\right.$
396.1 days), ${ }^{236} \mathrm{Pu}\left(T_{1 / 2}=2.858\right.$ years $)$, and ${ }^{237} \mathrm{Pu}$ ( $T_{1 / 2}=45.2$ days $)$ - convenient tracers for, e.g, studying the spread and biological pathways of neptunium and plutonium isotopes ejected into the environment in nuclear accidents. These studies involved measuring the cross sections of several direct and indirect reaction channels of $p$ and ${ }^{3} \mathrm{He}$ beams and ${ }^{236,238} \mathrm{U}$ and ${ }^{237} \mathrm{~Np}$ targets.

This work presents the results from experimental and theoretical studies on the formation cross sections of evaporation residues in the reaction ${ }^{235} \mathrm{U}+{ }^{3} \mathrm{He}$ at incident nucleus energies in the range of $20-42 \mathrm{MeV}$. The investigated reaction channels are listed in Table 1.

The cross sections of evaporation residue formation are analyzed using the direct reaction theory and

Table 1. Reactions studied in this work

\begin{tabular}{c|c|c|c}
\hline Reaction channel & $Q$ of reaction, MeV & Reaction product & $T_{1 / 2}[4]$ \\
\hline${ }^{3} \mathrm{He}, n$ & 2.7 & ${ }^{237} \mathrm{Pu}$ & $45.2(1)$ days \\
${ }^{3} \mathrm{He}, 2 n$ & -3.2 & ${ }^{236} \mathrm{Pu}$ & $2.858(8)$ years \\
${ }^{3} \mathrm{He}, 3 n$ & -10.6 & ${ }^{235} \mathrm{Pu}$ & $25.3(5)$ minutes \\
${ }^{3} \mathrm{He}, 4 n$ & -16.8 & ${ }^{234} \mathrm{Pu}$ & $8.8(1)$ hours \\
${ }^{3} \mathrm{He}, p n$ & -2.9 & ${ }^{236 m} \mathrm{~Np}$ & $22.5(4)$ hours \\
${ }^{3} \mathrm{He}, p 2 n$ & -8.6 & ${ }^{235} \mathrm{~Np}$ & $396.1(12)$ days \\
${ }^{3} \mathrm{He}, p 3 n$ & -15.6 & ${ }^{234} \mathrm{~Np}$ & $4.4(1)$ days \\
\hline
\end{tabular}


Table 2. Cross sections for the reactions ${ }^{235} \mathrm{U}\left({ }^{3} \mathrm{He}, n\right){ }^{237} \mathrm{Pu},{ }^{235} \mathrm{U}\left({ }^{3} \mathrm{He}, 2 n\right){ }^{236} \mathrm{Pu},{ }^{235} \mathrm{U}\left({ }^{3} \mathrm{He}, 2 n+p n \beta^{-}\right){ }^{236} \mathrm{Pu}$, and ${ }^{235} \mathrm{U}\left({ }^{3} \mathrm{He}, 4 n\right){ }^{234} \mathrm{Pu}$

\begin{tabular}{c|c|c|c|c}
\hline$E\left({ }^{3} \mathrm{He}\right), \mathrm{MeV}$ & $\sigma_{n}, \mathrm{mb}$ & $\sigma_{2 n}, \mathrm{mb}$ & $\sigma_{2 n+p n}, \mathrm{mb}$ & $\sigma_{4 n}, \mathrm{mb}$ \\
\hline $20.4(4)$ & $0.025 \pm 0.002$ & $2.0 \pm 0.5$ & $4.6 \pm 0.2$ & $0.10 \pm 0.13$ \\
$25.9(4)$ & $0.082 \pm 0.007$ & $5.2 \pm 1.2$ & $11.8 \pm 0.4$ & $0.2 \pm 0.2$ \\
$30.5(3)$ & $0.48 \pm 0.05$ & $5.7 \pm 0.8$ & $11.6 \pm 0.6$ & $0.25 \pm 0.03$ \\
$34.7(3)$ & $0.13 \pm 0.01$ & $4.2 \pm 0.8$ & $9.0 \pm 0.3$ & $0.15 \pm 0.05$ \\
$38.5(3)$ & & $2.4 \pm 1.9$ & $7.6 \pm 0.5$ & \\
$42.0(2)$ & $0.15 \pm 0.01$ & $5.2 \pm 1.1$ & $9.5 \pm 0.4$ & \\
\hline
\end{tabular}

Table 3. Cross sections for reactions ${ }^{235} \mathrm{U}\left({ }^{3} \mathrm{He}, p n\right){ }^{236 m} \mathrm{~Np},{ }^{235} \mathrm{U}\left({ }^{3} \mathrm{He}, p 2 n+3 n(\mathrm{EC})\right)^{235} \mathrm{~Np}$ and ${ }^{235} \mathrm{U}\left({ }^{3} \mathrm{He}, p 3 n\right){ }^{234} \mathrm{~Np}$

\begin{tabular}{c|c|c|c}
\hline$E\left({ }^{3} \mathrm{He}\right), \mathrm{MeV}$ & $\sigma_{p n}, \mathrm{mb}$ & $\sigma_{p 2 n+3 n}, \mathrm{mb}$ & $\sigma_{p 3 n}, \mathrm{mb}$ \\
\hline $20.4(4)$ & $5.4 \pm 0.9$ & $9 \pm 3$ & $0.02 \pm 0.12$ \\
$25.9(4)$ & $14 \pm 3$ & $22 \pm 6$ & $1.1 \pm 0.2$ \\
$30.5(3)$ & $12.3 \pm 1.5$ & $25 \pm 7$ & $2.2 \pm 0.3$ \\
$34.7(3)$ & $10.1 \pm 1.5$ & $20 \pm 6$ & $4.7 \pm 0.7$ \\
$38.5(3)$ & $11 \pm 4$ & & $6.76 \pm 0.08$ \\
$42.0(2)$ & $9 \pm 3$ & $13 \pm 4$ & $5.87 \pm 0.07$ \\
\hline
\end{tabular}

statistical theory that includes a two-component preequilibrium model.

\section{EXPERIMENTAL}

Highly enriched (isotope purity, $99.992 \%$ ) ${ }^{235} \mathrm{U}$ targets around $1 \mathrm{mg} \mathrm{cm}^{-2}$ thick were prepared via the repeated thermal decomposition of uranium nitrocellulose on a $0.1-\mathrm{mm}$-thick aluminum substrate [6]. The targets were bombarded with ${ }^{3} \mathrm{He}$ ions on the K130 cyclotron of the Accelerator Laboratory of University of Jyväskylä. The ion energy was set using a system of degrader foils introduced into the ion beam between consecutively arranged targets. The total number of ions was measured with a current integrator.

After exposure, the targets were left to cool for one-two days in order to allow the shortest-lived fission products to decay. They were then analyzed with gamma and alpha spectrometers. The targets were dissolved, and the neptunium and plutonium fission products were chemically separated from the target material using TRU Spec resin (Eichrom Technologies Inc., United States [7]); the details of the separation procedure can be found in [2]. The activity of the separated reaction products was measured. The activities of the isotopes ${ }^{234} \mathrm{~Np}$ and ${ }^{236} \mathrm{Pu}$ measured before and after their chemical separation were used to determine their chemical yields. This allowed us to calculate their reaction cross sections from the resulting activity data.

The decay parameters used to calculate the cross sections were borrowed from $[5,8,9]$. The final cross sections are listed in Tables 2 and 3. Since 48(1)\% of the ${ }^{236 m} \mathrm{~Np}$ nuclei were transformed into ${ }^{236} \mathrm{Pu}$ through beta decay, the measured cross sections for ${ }^{236} \mathrm{Pu}$ were produced by two mechanisms: reactions $\left({ }^{3} \mathrm{He}, 2 n\right)$ and $\left({ }^{3} \mathrm{He}, p n \beta^{-}\right)$. The cross section of reaction $\left({ }^{3} \mathrm{He}, 2 n\right)$ is thus found by subtracting the activity associated with the beta decay of ${ }^{236 m} \mathrm{~Np}$. The formation cross section of ${ }^{235} \mathrm{~Np}$ is in turn due to a combination of reaction $\left({ }^{3} \mathrm{He}, p 2 n\right)$, which leads directly to ${ }^{235} \mathrm{~Np}$, and electron capture in the short-lived isotope ${ }^{235} \mathrm{Pu}$ produced by the reaction $\left({ }^{3} \mathrm{He}, 3 n\right)$. The activity of ${ }^{235} \mathrm{Pu}$ was not measured in this experiment.

\section{THEORETICAL ANALYSIS}

The interaction between an incident ${ }^{3} \mathrm{He}$ nucleus and actinides is a complex combination of different nuclear processes, including direct reactions and preequilibrium and equilibrium statistical decays of highly excited compound nuclei that at the same time are highly prone to fission. The yield cross sections of the evaporation residues were calculated using the FIPRODY (Fission PRODuct Yields) computer code developed on the basis of the modification of the unified statistical model proposed in [11]. A two-component exciton model was used to adequately describe the initial excitation energy and the mass and charge distributions of the compound nuclei formed in ${ }^{3} \mathrm{He}-$ induced reactions. The initial exciton states for a model with proton and neutron particle-hole components were taken in the form of $(2,0,1,0)$ configurations. Pre-equilibrium proton and neutron emissions started with the $(3,1,1,0)$ and $(2,0,1,0)$ exciton states. The evolution of the exciton states and the emission of 


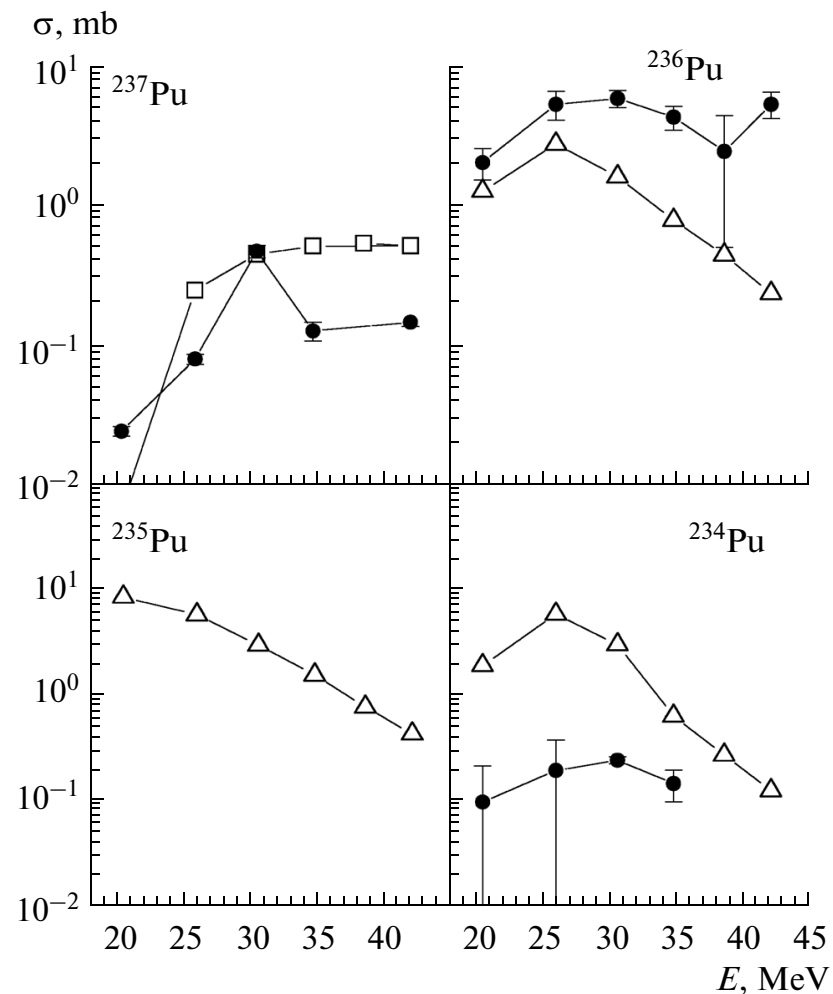

Fig. 1. Comparison between the experimental cross sections of formation for evaporation residues and their calculated values in the reaction ${ }^{235} \mathrm{U}+{ }^{3} \mathrm{He}$ at different energies. Data points represent the experimental values; triangles, calculations using the FIPRODY program; squares, calculations using the FRESCO code.

the particles were modeled using the Monte Carlo technique (the details of the procedure can be found in [11]).The decay of the compound nuclei was described by a statistical model that included shell effects and the pairing effect, along with nuclear friction in the fission channel. The calculation results included neutron and proton spectra and the cross sections of evaporation residue formation and fission. Figure 1 compares the calculated cross sections of evaporation residue formation (triangles) with their experimental values (data points with error intervals) for the plutonium isotopes. The calculated cross sections for ${ }^{237} \mathrm{Pu}$ lie below $10^{-2} \mathrm{mb}$, so the direct reaction mechanism is evidently important in this case. At the same time, we cannot explain the great difference between the experimental and theoretical values for the ${ }^{234} \mathrm{Pu}$ nucleus.

Figure 2 compares the calculated cross sections of evaporation residue formation (triangles) with the experimental data (data points with error intervals) for the neptunium isotopes. Independent and cumulative cross sections (stars) obtained using the calculated cross sections for ${ }^{235} \mathrm{Pu}$ are shown for the ${ }^{235} \mathrm{~Np}$ nucleus. The theoretical cross sections for ${ }^{236 m} \mathrm{~Np}$ are the sums of the isomeric and ground state cross sections. The iso-

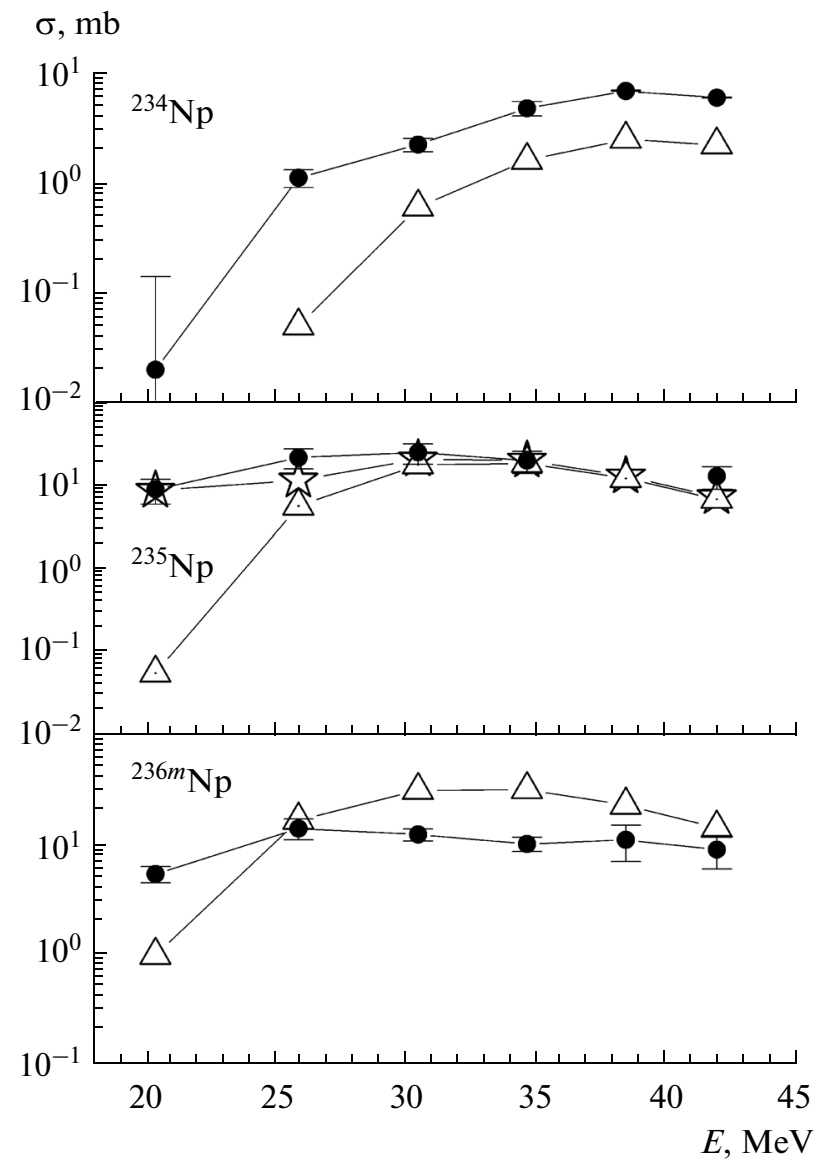

Fig. 2. Comparison between the experimental formation cross sections for the evaporation residues of $\mathrm{Np}$ isotopes and their calculated values in the reaction ${ }^{235} \mathrm{U}+{ }^{3} \mathrm{He}$ at different energies. Data points represent experimental values; triangles, calculations using the FIPRODY program; stars, calculations using the FIPRODY program with due regard for the decay of ${ }^{235} \mathrm{Pu}$.

meric ratio in the reaction ${ }^{235} \mathrm{U}\left({ }^{3} \mathrm{He}, p n\right){ }^{236} \mathrm{~Np}$ has yet to be measured.

For the isotope ${ }^{237} \mathrm{Pu}$, we measured the contribution from the direct reaction mechanism. The main process directly influencing the reaction cross section was stripping, the scheme of which is presented in Fig. 3. To estimate the cross section in this reaction channel, we used the Born approximation for the distorted waves of the FRESCO computer code [12]. This code is an version of the coupled channel method in which allowance can be made for nuclear excitations and interactions of finite action radius between different reaction channels; i.e., the program enables us to calculate most of the direct reactions that can be described within the coupled channel formalism: collective and solitary excitations, stripping and pickup reactions, and multistep mechanisms and combinations thereof. In our calculations, it was assumed that the nuclei were spherically symmetric and in their ground states. The energy-dependent global optical 


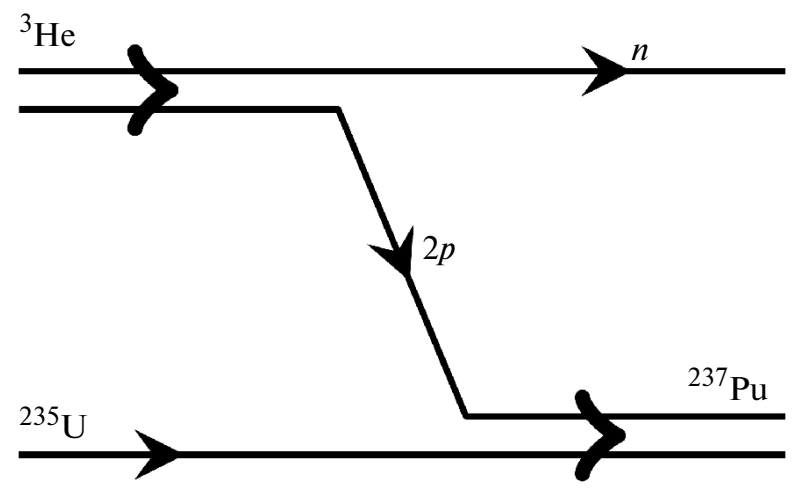

Fig. 3. Schematic diagram of the direct mechanism for the reaction ${ }^{235} \mathrm{U}\left({ }^{3} \mathrm{He}, n\right){ }^{237} \mathrm{Pu}$.

potentials describing the interaction between nuclei, ${ }^{3} \mathrm{He}$ nucleons, and deuterons were used as the input and output channel potentials [13-15]. The characteristic wave functions were generated with the generally accepted Woods-Saxon potential, the depth of which was varied in order to reconstruct the binding energy of the particle being transformed. The results from calculating the reaction cross section for the isotope ${ }^{237} \mathrm{Pu}$ are presented in Fig. 1 (squares). The direct reaction mechanism made only slight contributions for the other $\mathrm{Pu}$ and $\mathrm{Np}$ isotopes.

\section{CONCLUSIONS}

Investigations of the reaction ${ }^{235} \mathrm{U}+{ }^{3} \mathrm{He}$ began late in the 1970s with the irradiation of ${ }^{235} \mathrm{U}(50.3 \%)$ and ${ }^{238} \mathrm{U}(99.7 \%)$ targets with a ${ }^{3} \mathrm{He}$ beam having an energy of 21.9-27.0 MeV on the MGC-20 cyclotron [10]. The primary objective was to obtain the isotope ${ }^{237} \mathrm{Pu}$ as a tracer for environmental studies. In these experiments, the cross sections of the reactions ${ }^{235} \mathrm{U}\left({ }^{3} \mathrm{He}, 2 n\right){ }^{236} \mathrm{Pu}$ and ${ }^{235} \mathrm{U}\left({ }^{3} \mathrm{He}, n\right){ }^{237} \mathrm{Pu}$ were found to be 5.5(10) $\mathrm{mb}$ and $1.6(5) \mathrm{mb}$, respectively, at a ${ }^{3} \mathrm{He}$ ion energy of $27 \mathrm{MeV}$. These values agree satisfactorily with the ones obtained in this work. A theoretical analysis of the cross sections for the formation of evaporation residues in the reactions between ${ }^{3} \mathrm{He}$ and actinides was simultaneously performed for the first time. The yield of the evaporation residues depended strongly on the fission channel. To improve our theoretical predictions, additional measurements must be made of the fission characteristics, specifically the proton and neutron energies spectra and angular distributions.

\section{ACKNOWLEDGMENTS}

This work was supported by the Academy of Finland, contract nos. 112798 and 121049; by the Finnish Center for Advanced Programs of 2006-2011, project no. 213503; and by the Nuclear and Accelerator Physics program of the Department of Physics, University of Jyväskylä.

\section{REFERENCES}

1. Back, B.B., Britt, H.C., Hansen, O., et al., Phys. Rev. C, 1974, vol. 10, p. 1948.

2. Aaltonen, J., Dendooven, P., Gromova, E.A., et al., Radiochim. Acta, 2003, vol. 91, p. 557.

3. Aaltonen, J., Gromova, E.A., Helariutta, K., et al., Radiochim. Acta, 2005, vol. 93, p. 377.

4. Gromova, E., Jakovlev, V., Aaltonen, J., et al., Proc. Int. Nuclear Data Conf. for Science and Technology, New York, 2013, p. 227.

5. http://ie.lbl.gov/toi

6. Drapchinsky, L.V., Kuzmina, T.E., and Soloviev, S.M., Nucl. Instrum. Methods Phys. Res., Sect. A, 1999, vol. 438, p. 116.

7. Horwitz, E.P., Chiarizia, R., Dietz, M.L., et al., Anal. Chim. Acta, 1993, vol. 281, p. 361.

8. www.nndc.bnl.gov/nndcscr/pc_prog/

9. Chechev, V.P., Kuz'menko, N.K., Sergeev, V.O., and Artamonova, K.P., Otsenennye znacheniya yaderno-fizicheskikh kharakteristik transuranovykh radionuklidov: Spravochnik (Estimated Values of Nuclear Physical Characteristics of Transuranium Radionuclides. Handbook), Moscow: Energoatomizdat, 1988.

10. Aaltonen, J., Haaparanta, M., Kulha, M., et al., J. Radioanal. Chem., 1981, vol. 64, p. 73.

11. Rubchenya, V.A., Phys. Rev. C, 2007, vol. 75, p. 054601.

12. Thompson, I.J., Comput. Phys. Rep., 1988, vol. 7, p. 167.

13. Han, Y., Xu, Y., Liang, H., et al., Phys. Rev. C, 2010, vol. 81, p. 024616.

14. Xu, Y., Guo, H., Han, Y., et al., Sci. China: Phys., Mech. Astron., 2011, vol. 54, no. 11, p. 2005.

15. An, H. and Cai, C., Phys. Rev. C, 2006, vol. 73, p. 054605 .

Translated by S. Kittell 